\title{
XPS study of oxide nucleation and growth mechanisms on a model FeCrNiMo stainless steel surface
}

\author{
Benjamin Lynch, Frédéric Wiame, Vincent Maurice*, Philippe Marcus** \\ PSL Research University, CNRS - Chimie ParisTech, Institut de Recherche de Chimie Paris (IRCP), Physical \\ Chemistry of Surfaces Group, 11 rue Pierre et Marie Curie, 75005 Paris, France.
}

\begin{abstract}
High resolution X-ray photoelectron spectroscopy analysis has been used to investigate, in-situ, the mechanisms for oxide nucleation and growth on a FeCrNiMo single crystal alloy. Ultra-high vacuum conditions provided the ideal environment in which an oxide-free surface could be oxidised in a controlled manner, using extremely low pressures and step-wise exposures of oxygen. In-situ snapshot measurements, which records an XPS spectrum every $10 \mathrm{~s}$, provided insight into the mechanisms of chromium and nitrogen segregation during annealing of the sample. High resolution XPS spectra was used to follow the evolution of the key elements at step-wise intervals, allowing for detailed insights into the nucleation and growth mechanisms. Angular XPS analysis provided further information on the in-depth distribution and stratification of the oxide film.

Keywords: Stainless steel; corrosion protection; initial oxidation; mechanism; oxide film; XPS
\end{abstract}

\section{Introduction}

Owed to their wide range of properties, stainless steels are a group of iron-based alloys that have helped create the twenty-first century as we know today. This ability to shape the world around us is not just thanks to their malleability and ductility, but also to their remarkable strength and resistance to corrosion. One class of stainless steel of high importance is the 300 series, which contains two key alloys - FeCrNi and FeCrNiMo, commonly known as 304 and 316, respectively. These austenitic alloys contain significant amounts of chromium and nickel, and are the most commonly used class of stainless steels, being common place in household appliances and architecture. The reason behind the remarkable resistance to corrosion is the formation of a passive film at the surface, which isolates the bare metal from its environment. This thin protective layer, of just a

\footnotetext{
${ }^{*}$ Corresponding author email: vincent.maurice@chimieparistech.psl.eu

** Corresponding author email: philippe.marcus@chimieparistech.psl.eu
} 
few nanometres in thickness, that consists of a mixture of oxides and hydroxides is found to be enriched in $\mathrm{Cr}^{3+}$ species [1-5], an effect that is further enhanced in acidic media due to the preferential dissolution of iron oxide in low pH environments [6-9]. Conversely, in basic media we do not see such an enrichment of chromium, but rather a much thicker, iron-rich film [9-11]. Unfortunately, the passive film is not completely impenetrable and localised breakdown can occur, leading to a phenomenon known as pitting corrosion if the film does not self-repair [12-14]. This can have devastating consequences when it comes to the reliability of the material and can endanger the environment as well as the safety of the population. Reparations and prevention of damage owed to corrosion can come at a significant cost $[15,16]$. To help combat the localised breakdown of the film and pitting corrosion, small amounts of molybdenum can be added to improve resistance to corrosion $[2,6,17-22]$. The molybdenum-containing 316 stainless steel is most commonly deployed in environments that are rich in aggressive anions, such as chlorides, that can cause significant pitting to occur. The exact role that molybdenum plays in combatting localised corrosion is still debated despite extensive research; some suggest that molybdenum promotes passive film repair [23-27], whilst others say that it aids in preventing the breakdown of the film in the first place $[6,17,21,22,27]$.

Recent work has shown that the distribution of chromium oxide within the passive film is not homogeneous and that the local heterogeneities, that have been shown to form during the initial growth of the oxide, may be areas where localised breakdown can occur $[2,28]$. Due to these recent discoveries, it has been proposed that the very initial oxidation of the stainless steels, detailing the mechanism of oxide nucleation and growth, may contain key information that we can use to better prepare these alloys in their fight against corrosion. Work by Ma et al. has investigated the step-wise growth of the oxide formed on FeCrNi (100)-oriented single crystals at low exposures of oxygen $\left(0-100 \mathrm{~L}\left(1 \mathrm{~L}=1.33 \times 10^{-6} \mathrm{torr} \cdot \mathrm{s}\right)\right)$ using both scanning tunneling microscopy (STM) [29-31] and X-ray photoelectron spectroscopy (XPS) [32], studying both the structure and chemical composition. These studies highlighted that the oxide growth is not homogeneous but with preferential sites for chromium and iron oxidation that will later lead to heterogeneities within the 3D oxide. Further work looking at how pre-oxidation in a controlled environment effects the passive film has been shown to improve its overall performance when compared with passive films formed by electrochemical alteration of native oxides $[7,8,33]$.

To the best of the authors' knowledge, the present work reports new insight into the mechanism of initial oxide growth on molybdenum-containing austenitic stainless steel alloys at such low 
exposures of oxygen. The following investigation highlights the step-wise oxidation of a FeCrNiMo (100)-oriented single crystal (a model of 316 stainless steel) at low pressure $\left(<5 \times 10^{-8}\right.$ mbar) and exposures of oxygen $(0-100 \mathrm{~L})$ at both room temperature and $250{ }^{\circ} \mathrm{C}$. XPS, both in-situ and ex-situ, has been used to monitor kinetics of element segregation during surface preparation as well as to give information on the evolution of both the composition and stratification of the oxide after step-wise exposures to oxygen. The aim of this work is to provide a deeper understanding of the growth of oxide films on stainless steels and how to best use this information to improve passivity and resistance to localised breakdown of the passive film.

\section{Experimental}

Surface preparation and analysis was carried out on a (100)-oriented single crystal of composition Fe-18Cr-14Ni-1.3Mo (at.\%). The single crystal, synthesised at École des Mines de Saint Étienne, can be considered as a model sample of AISI 316L. Before introduction to the ultra-high vacuum system (UHV) the surface was mechanically polished down to 0.25 micron finish with diamond paste.

All experiments were performed in a multi-chamber UHV system consisting of one preparation and two analysis chambers. Within the system, XPS, STM and low energy electron diffraction (LEED) could be performed. A base pressure of less than $10^{-10}$ mbar was maintained throughout. Prior to oxidation, a clean surface was prepared via cycles of high energy $\operatorname{Ar}^{+}$sputtering $\left(P_{\mathrm{Ar}}=\right.$ $5 \times 10^{-6}$ mbar, $20 \mu \mathrm{A}, 1 \mathrm{keV}, 10$ minutes) and annealing $\left(700^{\circ} \mathrm{C}, 10\right.$ minutes) via radiative heating of the backside of the sample. The absence of surface contaminants was determined via XPS, with STM and LEED being used to verify the structural state of the surface prior to oxidation, displaying a characteristic $(\sqrt{2} \times \sqrt{2}) \mathrm{R} 45^{\circ}$ surface structure, details of which will be reported separately. Oxidation reactions were carried out in the analysis chamber at room temperature (RT) and $250{ }^{\circ} \mathrm{C}$, the later due to its relevance in industry. The surface temperature of the sample was measured indirectly using a thermocouple. Gaseous oxygen (99.999\%) was introduced to the analysis chamber via a leak valve, resulting in the oxidation of the clean sample. The pressure was continuously recorded, with $P_{\mathrm{O}_{2}}$ never exceeding $5 \times 10^{-8}$ mbar. Exposures of oxygen were calculated by integrating $P_{\mathrm{O}_{2}}$ as a function of the exposure time.

XPS analysis was performed using an Argus spectrometer and detector, both manufactured by Scienta Omicron. Monochromatic Al K $\alpha$ radiation $(\mathrm{h} \nu=1486.6 \mathrm{eV})$ was used as an X-ray source.

High resolution spectra of Fe 2p, Cr 2p, Ni 2p, Mo 3d, O 1s, N 1s and the Fermi level were recorded 
at take-off angles of $45^{\circ}$ and $90^{\circ}$, at pass energy of $20 \mathrm{eV}$ and a step size of $0.05 \mathrm{eV}$. The high resolution spectra were recorded after exposures of $0 \mathrm{~L}, 1 \mathrm{~L}, 3 \mathrm{~L}, 6 \mathrm{~L}, 10 \mathrm{~L}, 15 \mathrm{~L}$ and $25 \mathrm{~L}$ at both temperatures, with additional exposures of $35 \mathrm{~L}, 50 \mathrm{~L}, 75 \mathrm{~L}$ and $100 \mathrm{~L}$ at $250{ }^{\circ} \mathrm{C}$. Survey spectra were recorded at a pass energy of $50 \mathrm{eV}$ and a step size of $0.5 \mathrm{eV}$. Snapshot measurements were used to monitor the segregation of elements during the annealing process, with a spectrum being recorded every $10 \mathrm{~s}$, allowing for in real time monitoring of kinetics. The Fermi level was used as a reference for all binding energies.

Casa XPS software was used for the peak fitting process [34]. A self-consistent approach was applied. More details on the fitting procedure can be found elsewhere [7, 8, 32]. An adjustable Shirley background was used throughout. The fitting parameters (binding energy (BE), and full width at half maximum (FWHM)) used for Fe $2 \mathrm{p}_{3 / 2}$, Cr $2 \mathrm{p}_{3 / 2}, \mathrm{Ni} 2 \mathrm{p}_{3 / 2}$, Mo $3 \mathrm{~d}_{5 / 2}$ and N 1s peaks are found in Table 1. For the sake of clarity, intensity contributions from satellite peaks were taken into account in the quantification results, as suggested by Brundle and Crist [35]. Error bars that are associated with the XPS results were estimated based on fit adjustment. This was achieved by making small alterations to the background, the largest source of error, whilst still maintaining a good fit of the experimental data. Any differences in the relative concentrations of each component were noted. Changes in the values were minimal due to the strict fitting parameters.

\section{Results and discussion}

\subsection{The clean surface and element segregation}

As previously mentioned, cycles of $\mathrm{Ar}^{+}$sputtering and high temperature annealing were necessary in order to generate a clean and well-organised surface. The purpose of the former is to remove contaminants, whilst the latter is required in order to reorganise the surface structure. Previous work carried out on FeCrNi (100) surfaces has shown that annealing at a temperature of $700{ }^{\circ} \mathrm{C}$ is necessary if we are to produce a surface state that is well organised [30]. After sputtering was performed, only metallic iron, chromium, nickel and molybdenum (as well as traces of argon) were observed. A surface composition of $\mathrm{Fe}-13 \mathrm{Cr}-11 \mathrm{Ni}-3 \mathrm{Mo}$ was determined from survey spectra. During the annealing process it was found that chromium and nitrogen segregated, the latter present in trace amounts in the bulk, the kinetics of which were monitored using snapshot measurements, with the data shown in Figure 1. Figures $1 \mathrm{a}$ and $1 \mathrm{~b}$ show the change in Cr $2 \mathrm{p}$ and $\mathrm{N}$ 1s intensities as a function of time, respectively, whilst Figures 1c and 1d show the change in intensity of the chromium and nitrogen as a function of temperature, respectively. The intensity of the chromium 


\begin{tabular}{lllll}
\hline Core level & State & Assignment & $\mathrm{BE}( \pm 0.1 \mathrm{eV})$ & $\mathrm{FWHM}( \pm 0.1 \mathrm{eV})$ \\
\hline Mo $3 \mathrm{~d}_{5 / 2}$ & $\mathrm{Mo}^{0}$ & Metal & 227.6 & 0.6 \\
& $\mathrm{Mo}^{4+}$ & Oxide & 228.8 & 1.3 \\
& $\mathrm{Mo}^{6+}$ & Oxide & 232.3 & 1.8 \\
\hline $\mathrm{Cr} 2 \mathrm{p}_{3 / 2}$ & $\mathrm{Cr}^{0}$ & Metal & 573.9 & 1.2 \\
& $\mathrm{Cr}^{3+}$ & Oxide & 576.6 & 2.0 \\
& $\mathrm{Cr}^{3+}$ & Nitride & 575.5 & 1.8 \\
& $\mathrm{Cr}^{3+}$ & Satellite & 588.5 & 3.5 \\
\hline $\mathrm{Fe} 2 \mathrm{p}_{3 / 2}$ & $\mathrm{Fe}^{0}$ & Metal & 706.9 & 0.7 \\
& $\mathrm{Fe}^{2+}$ & Oxide & 708.3 & 1.6 \\
& $\mathrm{Fe}^{3+}$ & Oxide & 710.3 & 3.1 \\
& $\mathrm{Fe}^{2+}$ & Satellite & 712.8 & 3.8 \\
& $\mathrm{Fe}^{3+}$ & Satellite & 716.3 & 4.1 \\
\hline $\mathrm{Ni} 2 \mathrm{p}_{3 / 2}$ & $\mathrm{Ni}^{0}$ & Metal & 852.8 & 0.9 \\
& $\mathrm{Ni}^{0}$ & Satellite & 859.1 & 5.0 \\
\hline $\mathrm{N} 1 \mathrm{~s}$ & & $\mathrm{~N}_{s}$ (surface nitride) & 396.6 & 1.1 \\
& & $\mathrm{~N}_{b}$ (bulk nitride) & 397.2 & 0.7 \\
& & $\mathrm{~N}_{i}$ (interstitial nitrogen) & 397.8 & 0.7 \\
& & $\mathrm{~N}_{m}$ (minority nitrogen $)$ & $398.5-400.5$ & $1.8-6$ \\
\hline
\end{tabular}

Table 1: XPS peak fitting parameters obtained for reconstruction of spectra. 
begins to increase at $300{ }^{\circ} \mathrm{C}$, marked by the red dashed line in Figure 1c, with the chromium intensity increasing steadily until approximately $610{ }^{\circ} \mathrm{C}$. Beyond this temperature, the rate of chromium segregation appears to increase, indicated with the dashed blue line. These two phases may be an indication of two different mechanisms for chromium segregation during annealing of stainless steel samples. The intensity of the signal did not diminish during the cooling of the sample, evidenced by the relative intensity remaining high as the temperature cools back down, in Figure 1c.

With regards to the increase in intensity of the nitrogen, we see no significant change in the intensity until we are around $600{ }^{\circ} \mathrm{C}$, indicated by the dashed blue line in Figure 1d, which is the point at which we see the second increase in the rate of chromium segregation, suggesting cosegregation of the elements, which has also been reported elsewhere on both ferritic and austenitic stainless steels $[29,30,32,36]$. Any apparent changes in nitrogen intensity below this temperature cannot really be considered due to the high level of noise, although no segregation of nitrogen was reported below this temperature on similar surfaces [32]. The rate of nitrogen segregation reaches its maximum value between 600 and $700{ }^{\circ} \mathrm{C}$, which is the same range as that of the chromium, further reinforcing the evidence of co-segregation. After the annealing process has finished we see a dramatic change in the composition of the surface, now determined as $\mathrm{Fe}-30 \mathrm{Cr}-7 \mathrm{Ni}-2 \mathrm{Mo}-7 \mathrm{~N}$. It has been suggested in previous work that the chromium and nitrogen co-segregation results in the formation of chromium nitride components that promote selective oxidation of chromium $[30,32,37]$. The time taken to reach $700{ }^{\circ} \mathrm{C}$, as well as the time spent at this temperature, were found not to have an influence on the co-segregation of the elements. Whilst not shown in Figure 1d, cooling the sample was not found to result in a decrease of the $\mathrm{N}$ 1s signal.

\subsection{Initial oxidation}

A selection of high resolution XPS spectra recorded at $250{ }^{\circ} \mathrm{C}$ between $0-100 \mathrm{~L}$ are shown in Figure 2. Figure 2a shows Fe 2p spectra fitted with three components, metallic Fe, and oxidised $\mathrm{Fe}^{2+}$ and $\mathrm{Fe}^{3+}$. Similarly, in Figure $2 \mathrm{~b}$ where the $\mathrm{Cr} 2 \mathrm{p}$ spectra are shown we also identify three components which are assigned as metallic $\mathrm{Cr}$ and $\mathrm{Cr}^{3+}$, present as both an oxide and nitride. With regards to the Mo 3d spectra shown in Figure 2c we have metallic Mo, and oxidised $\mathrm{Mo}^{4+}$ and $\mathrm{Mo}^{6+}$. Nickel was not found in an oxidised form at any point in the process, which can be expected given its high enthalpy of formation relative to those of iron, chromium and molybdenum [38]. A selection of the high resolution spectra of the $\mathrm{Ni} 2 \mathrm{p}$ region can be found in the supplementary information. Peak fitting analysis of exposures 0-3 L was not performed as the uncertainty in the 
Chromium segregation
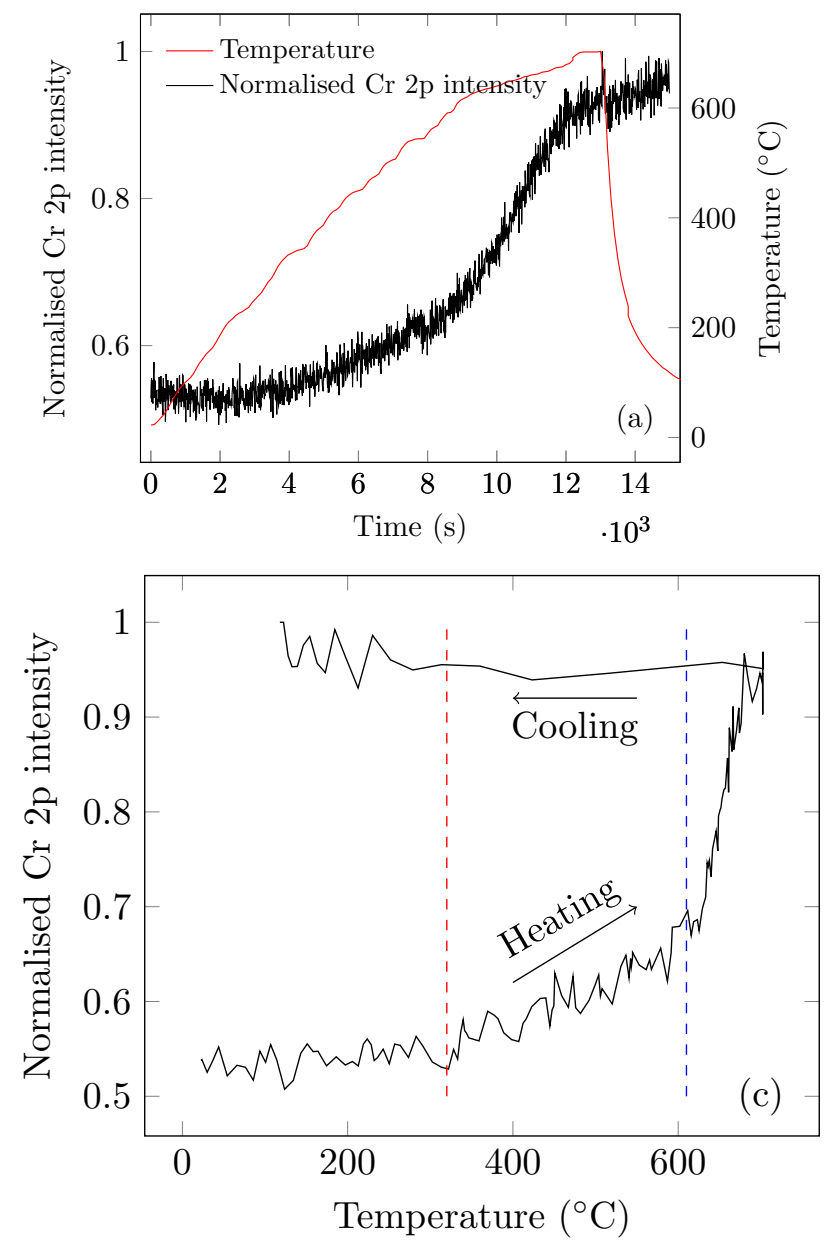

Nitrogen segregation
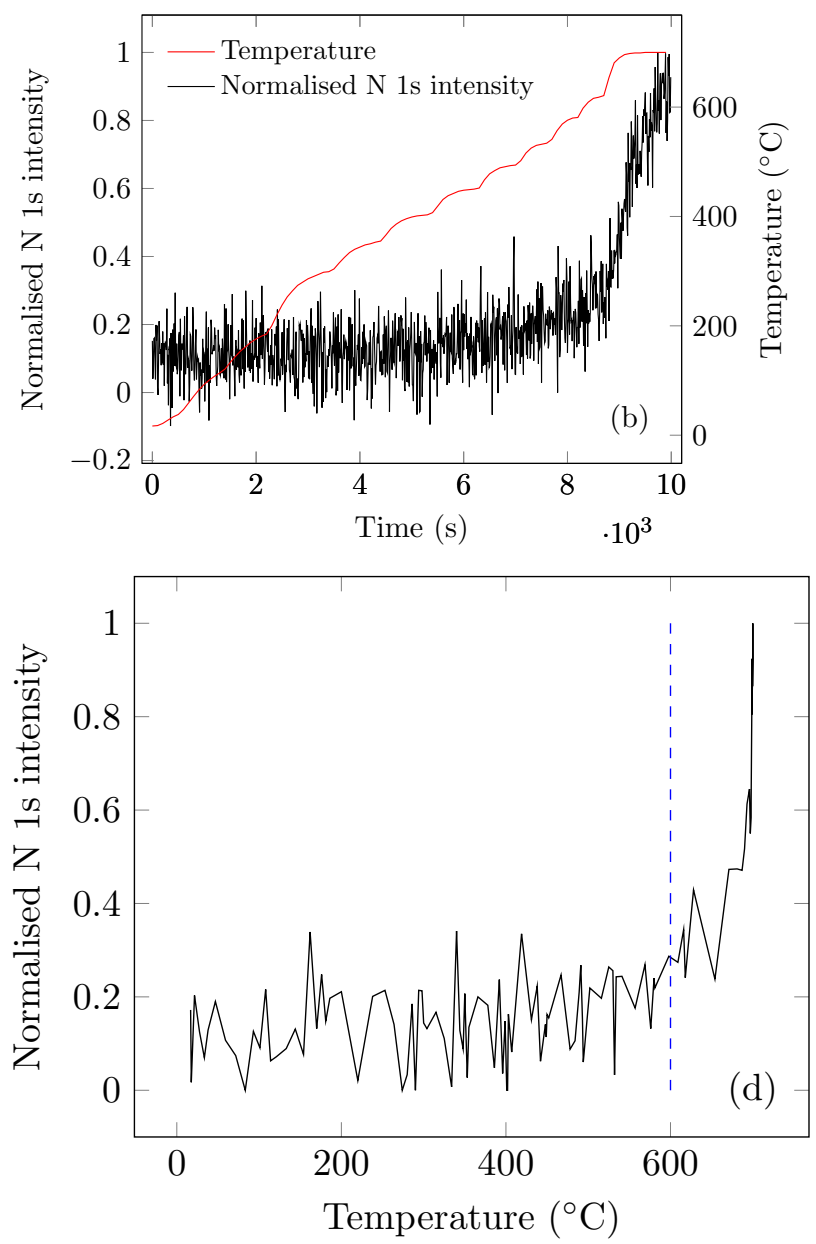

Figure 1: Real-time segregation of elements during the annealing process as measured using XPS snapshot measurements: (a) variation of normalised Cr $2 \mathrm{p}$ intensity, (b) variation of normalised N 1s intensity, (c) Normalised Cr $2 p$ intensity as a function of annealing temperature, (d) Normalised $\mathrm{N}$ 1s intensity as a function of annealing temperature. 
(a) Fe $2 p$
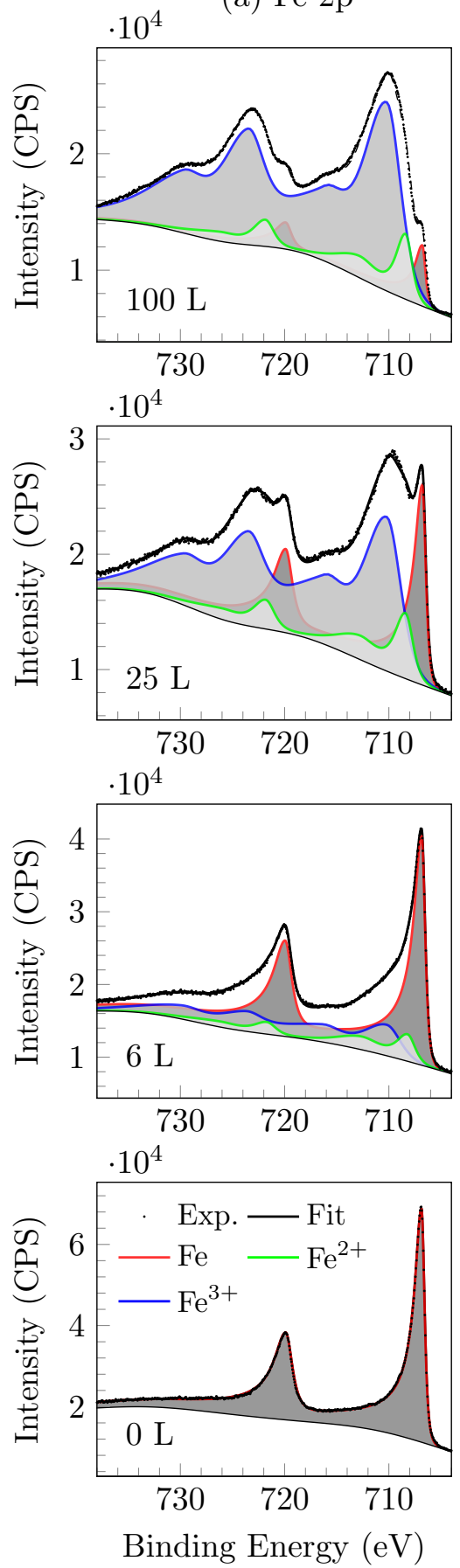

(b) $\operatorname{Cr} 2 p$
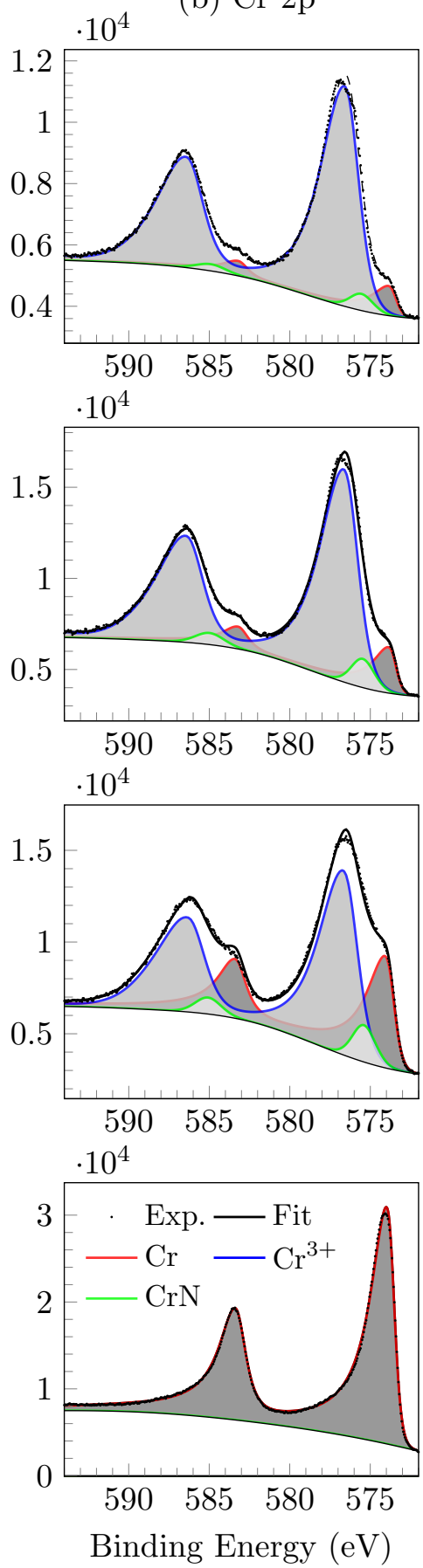

(c) Mo 3d
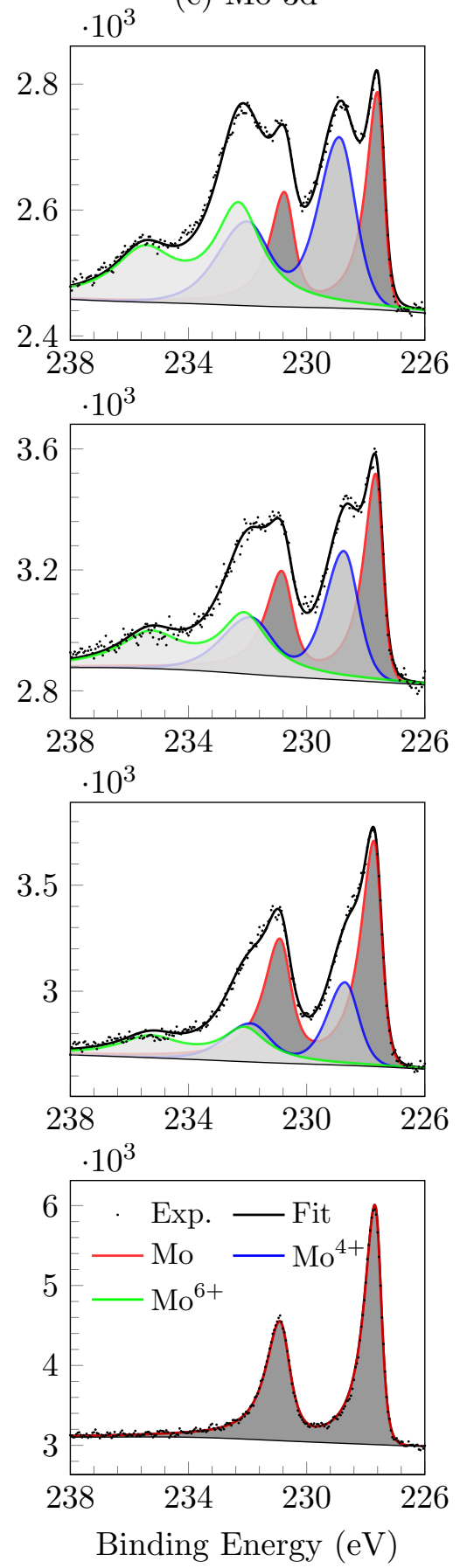

Figure 2: High resolution XPS spectra of (a) iron, (b) chromium and (c) molybdenum recorded after oxygen exposures of $0,6,25$ and $100 \mathrm{~L}$ at $250{ }^{\circ} \mathrm{C}$. 
process was too large when compared with the small changes in the peak shape. Instead, a method of normalising and comparing the experimental curves obtained was applied, allowing us to observe the changes without direct assignment. In order to do this, the binding energy of all individual spectra were calibrated with reference to the Fermi Level and a constant background associated with the flat, low intensity part of the spectra was subtracted. The the maximum intensity was then normalised to one. If we first consider exposures made at RT, after $1 \mathrm{~L}$ of oxygen there is no apparent change in the shape of the iron (Figure 3a), chromium (Figure 3b) or molybdenum (Figure 3c) spectra. As shown in Figure 4, at $1 \mathrm{~L}$, there is an increase in the relative intensity (0.06) of the $\mathrm{O}$ 1s signal (see supplementary information for $\mathrm{O}$ 1s high resolution spectra from 0-3 L), indicating that oxygen is interacting with the surface. This change can be attributed to a mixture of physisorption, and the beginnings of oxide nucleation at levels that are undetectable in the metallic spectra. It is after we increase the exposure to $3 \mathrm{~L}$ that we observe the first changes in the iron and chromium spectra, with molybdenum remaining unchanged. At this stage it is impossible to relate these changes to particular chemical species with any great certainty. With regards to iron it is highly likely that we are observing the nucleation of $\mathrm{Fe}^{2+}$ and $\mathrm{Fe}^{3+}$ oxides, such as $\mathrm{FeO}$ and $\mathrm{Fe}_{2} \mathrm{O}_{3}$, the two most common iron based oxides formed on stainless steels [5, 39]. However, the formation of mixed valence and non-stoichiometric oxides cannot be ruled out at such an early stage of the oxide growth process. Lin et al. [40] have previously suggested that under exposures of $50 \mathrm{~L}$ on polycrystalline iron surfaces the nucleating oxide of iron is $\mathrm{FeO}_{x}(x=0.67-1)$ which becomes $\mathrm{Fe}_{3} \mathrm{O}_{4}$ after further exposure to oxygen. Ma et al. [32] have recently reported a ratio of 1.4 of $\mathrm{Fe}^{3+} / \mathrm{Fe}^{2+}$ after an exposure of $3 \mathrm{~L}$ at $\mathrm{RT}$ on a $\mathrm{FeCrNi}(100)$ surface. Analysis of the chromium at such an early stage is even more difficult, owed to the complex nature of CrN species, which we must first discuss. XPS spectra of the nitrogen 1s region for the first three langmuirs at both RT and $250{ }^{\circ} \mathrm{C}$ are shown in Figure 5. Four main components have been assigned in the decomposition of each spectrum, as well as the presence of structures relating to Mo $3 \mathrm{p}_{3 / 2}$, which needed to be considered during the peak fitting process. Tentative assignments of each of these four components can be made with reference to previous work $[29,30,32,36,41-43]$. $\mathrm{N}_{s}$ is noted as two dimensional surface nitride, $\mathrm{CrN} ; \mathrm{N}_{i}$ as interstitial nitrogen; $\mathrm{N}_{b}$ as $3 \mathrm{D}$ clusters near the outermost surface, referred to as bulk nitride; and $\mathrm{N}_{m}$ as minority contributions (such as $\mathrm{N}-\mathrm{O}$ interactions). Figure 6a plots the evolution of the nitrogen components as a function of oxygen exposure at RT and from that we can see that on the clean surface, bulk nitride is by far the most common component, making up $67 \%$ of the total. However, upon the introduction of oxygen, a 
diminution of this peak is observed in conjunction with a rise in the relative amounts of surface and minority nitrogen, indicating that there is a change in the structure of the surface as a result of early oxidation. At RT, the change is initially slow before accelerating between 3 and $6 \mathrm{~L}$, with no significant changes observed after $15 \mathrm{~L}$ - the point at which the uptake of oxygen is significantly reduced, as evidenced in Figure 4 which shows the $\mathrm{O}$ 1s intensity as a function of oxygen exposure. Once we have reached saturation of the surface, the bulk nitride component is now the smallest contributor to the $\mathrm{N}$ 1s peak, now making up 16\%, which is more than four times less than on the clean surface. The increasing amounts of surface $\mathrm{CrN}$ is reflected in the $\mathrm{Cr} 2 \mathrm{p}$ spectra, which adds to the uncertainty when fitting of the chromium components at less than $3 \mathrm{~L}$. Therefore, we can only say that the changes in the chromium peaks at RT at these low exposures are due to the increasing presence of both chromium oxide (most likely $\mathrm{Cr}_{2} \mathrm{O}_{3}$ ) and surface CrN. At room temperature there is no obvious change in the molybdenum spectrum during the initial stages of oxidation of the stainless steel sample.

At $250{ }^{\circ} \mathrm{C}$ the rate of change in shape of the curves between $0-3 \mathrm{~L}$ is accelerated when compared to what was observed at RT, as shown in Figure 3, indicating a faster rate of reaction. This is also evidenced in Figure 4 where we have a higher relative intensity at $250{ }^{\circ} \mathrm{C}(0.29)$ than at $\mathrm{RT}$ (0.17) in the $\mathrm{O} 1 \mathrm{~s}$ spectra after an exposure of $3 \mathrm{~L}$. This result is contrary to the kinetic data shown in recent work on a $\mathrm{FeCrNi}(100)$ sample [32], where it was shown that the initial rate of reaction was quicker at room temperature owed to the nucleation phase of oxide growth being limited by oxygen adsorption. After an exposure of $1 \mathrm{~L}$ at $250{ }^{\circ} \mathrm{C}$, there is clear evidence of changes in the shape of both the iron and chromium species, with molybdenum still remaining unchanged (Figure 3). The observed changes can once again be attributed to a mixture of oxide growth, and in the case of the chromium, a change in the surface structure and the small augmentation of the amount of surface nitride present. It is after an exposure of $3 \mathrm{~L}$ that we see more significant changes to the spectra. We should first comment on the nitrogen spectra in Figure 5, where there the rate of change in the amount of bulk nitride to surface, minority and interstitial nitrogen is much quicker at this temperature than at RT. In Figure $6 \mathrm{~b}$ we can see that after $3 \mathrm{~L}$ surface nitride makes up approximately $11 \%$ of the total nitrogen area, compared to around $4 \%$ at room temperature. This rapid onset of surface nitride may go some way to explain the difference in reactivity, with surface chromium nitride being proposed as the nucleation site for $\mathrm{Cr}_{2} \mathrm{O}_{3}[29,30]$. As a result significant changes are observed in the chromium spectrum. We notice further change in the shape of the iron spectrum at binding energies associated with that of iron oxide, after an exposure of $3 \mathrm{~L}$, 
(a) Fe $2 p$
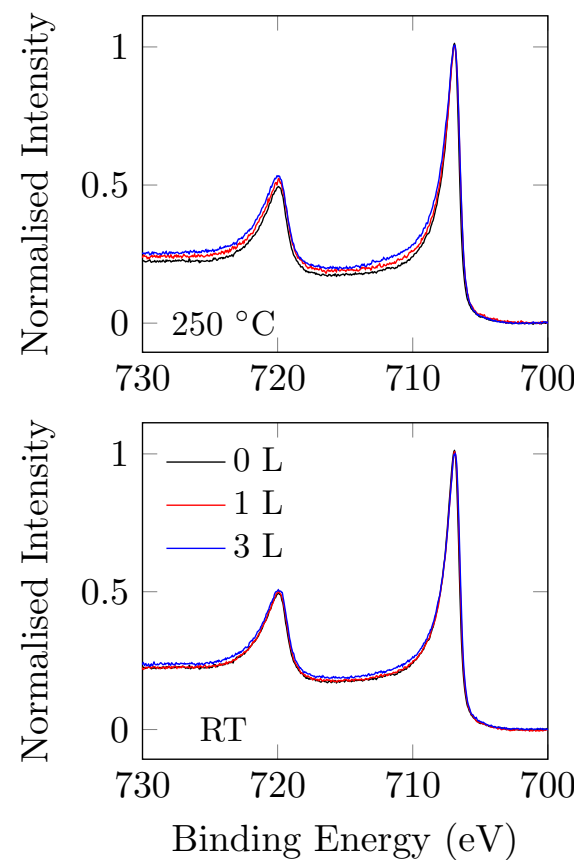

(b) $\operatorname{Cr} 2 \mathrm{p}$
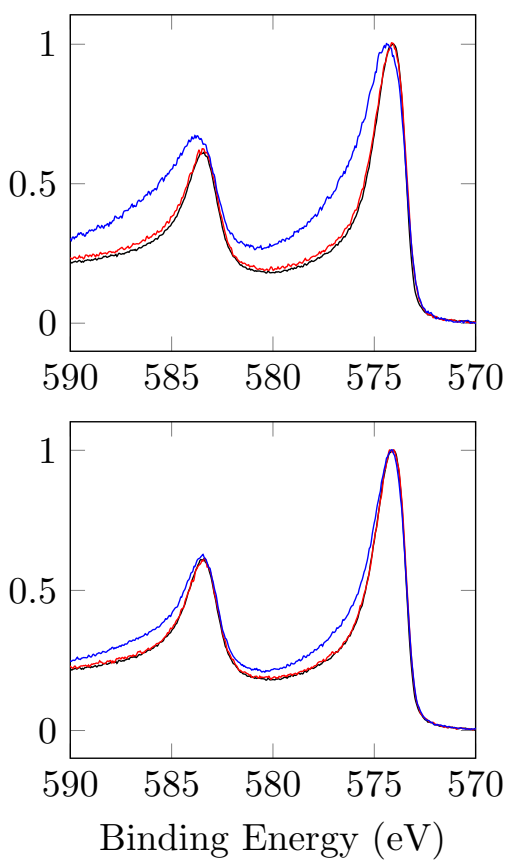

(c) Mo 3d
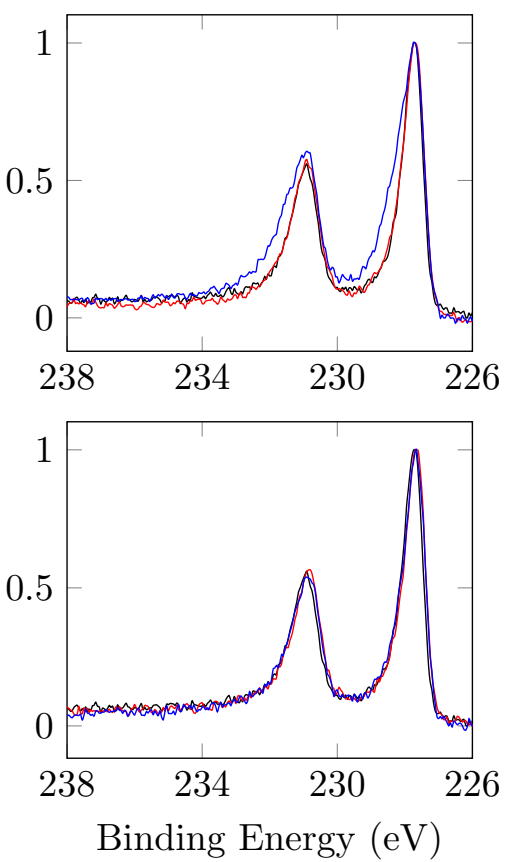

Figure 3: Comparison of peak shapes for (a) Fe 2p, (b) Cr 2p and (c) Mo 3d during the first $3 \mathrm{~L}$ of oxygen exposure at RT (top) and $250{ }^{\circ} \mathrm{C}$ (bottom).

which indicates further nucleation of iron-based oxides. It is at this point, after chromium and iron oxidation have already begun that we see the first notable changes in the molybdenum spectrum in Figure 3c, with an asymmetric broadening of Mo 3d peaks at higher binding energies relative to the metallic component at $227.6 \mathrm{eV}$, indicating that oxide formation has begun. The approximate position would indicate that it is a $\mathrm{Mo}^{4+}$ oxide; we would expect $\mathrm{Mo}^{6+}$ species to influence the shape of the curve at higher binding energies relative to that of what we observe. This is demonstrated by the fact that there are no differences in the shape of the curves at $236.5 \mathrm{eV}$, where one would expect to find a component that corresponds to $\mathrm{Mo}^{6+}$ for the $3 \mathrm{~d}_{3 / 2}$ core level $[7,8]$.

\subsection{Evolution of the elements}

At exposures greater than $3 \mathrm{~L}$, we can have more confidence in the assignment of changes in the XPS spectra. Figure 7 shows the evolution of the relative intensities of (a) iron, (b) chromium and (c) molybdenum as a function of the oxygen exposure. We shall first consider the evolution of the elements at room temperature. As discussed above, $\mathrm{Cr}^{3+}$ is owed to the presence of $\mathrm{Cr}_{2} \mathrm{O}_{3}$, although mixed oxide species cannot be discounted. At no point in the process, at both RT and at $250{ }^{\circ} \mathrm{C}$, is chromium found in its +6 oxidation state. If it were present, we would expect a peak at 


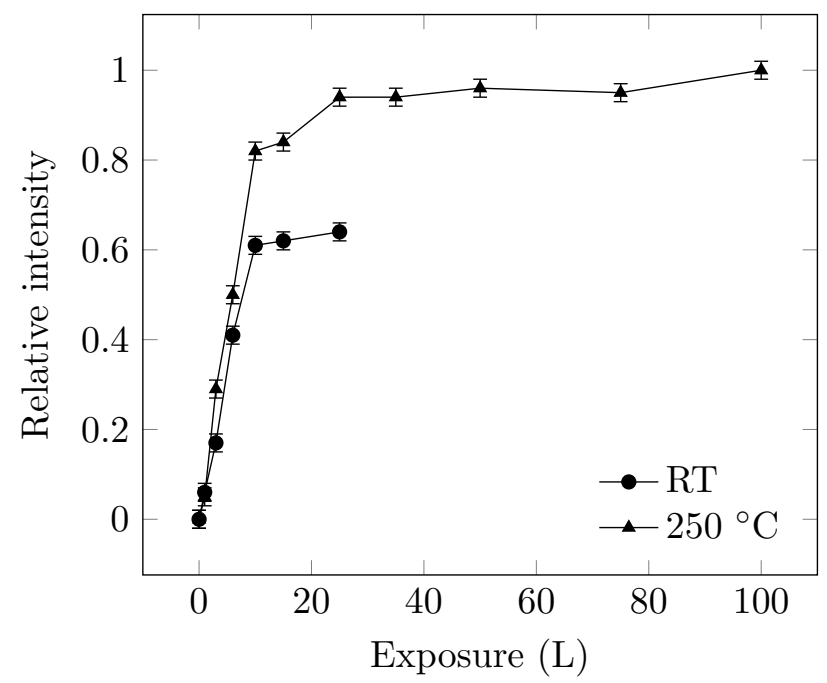

Figure 4: Relative intensity of $\mathrm{O} 1 \mathrm{~s}$ signal plotted as a function of oxygen exposure at both $\mathrm{RT}$ and $250{ }^{\circ} \mathrm{C}$.

(a) $0 \mathrm{~L}$

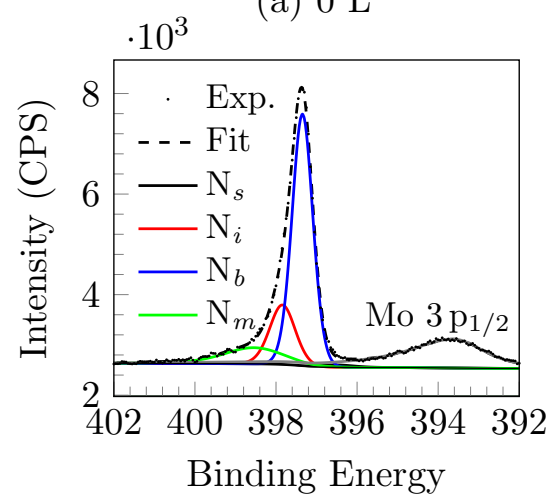

(b) $1 \mathrm{~L}$
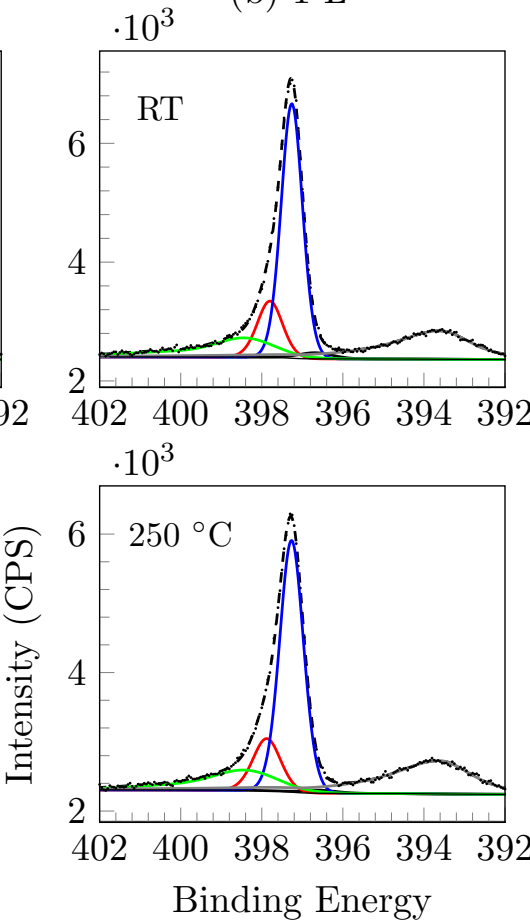

(c) $3 \mathrm{~L}$
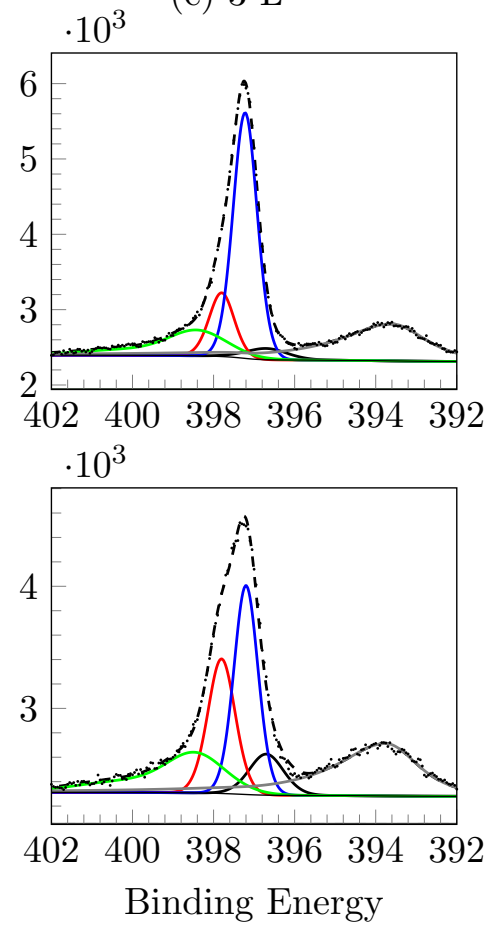

Figure 5: High resolution XPS spectra of the $\mathrm{N}$ 1s region during the first $3 \mathrm{~L}$ of oxygen exposure at both RT (top) and $250{ }^{\circ} \mathrm{C}$ (bottom), showing the four identified components, $\mathrm{N}_{s}$ (surface nitride), $\mathrm{N}_{i}$ (interstitial nitrogen), $\mathrm{N}_{b}$ (bulk nitride) and $\mathrm{N}_{m}$ (minority nitrogen). 
(a)

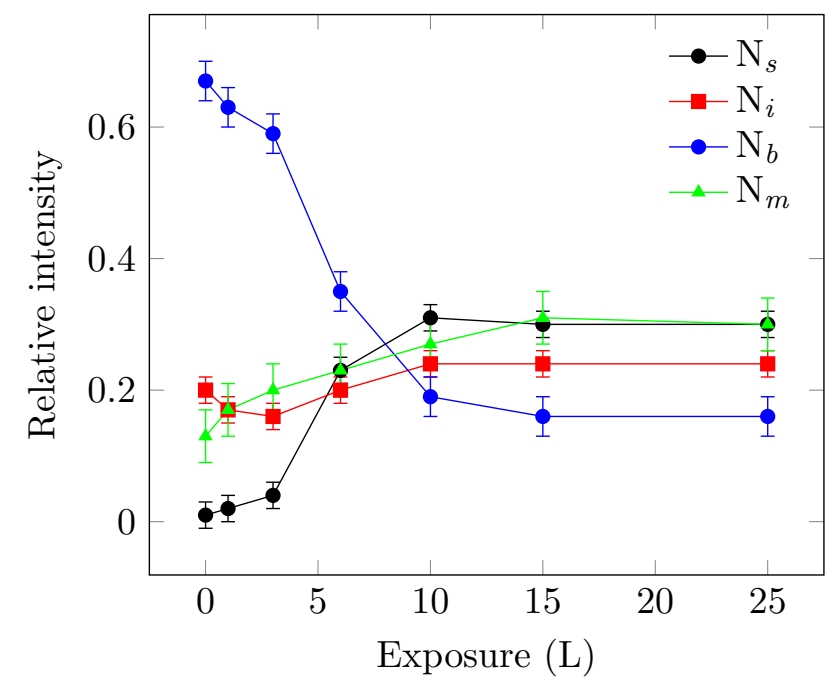

(b)

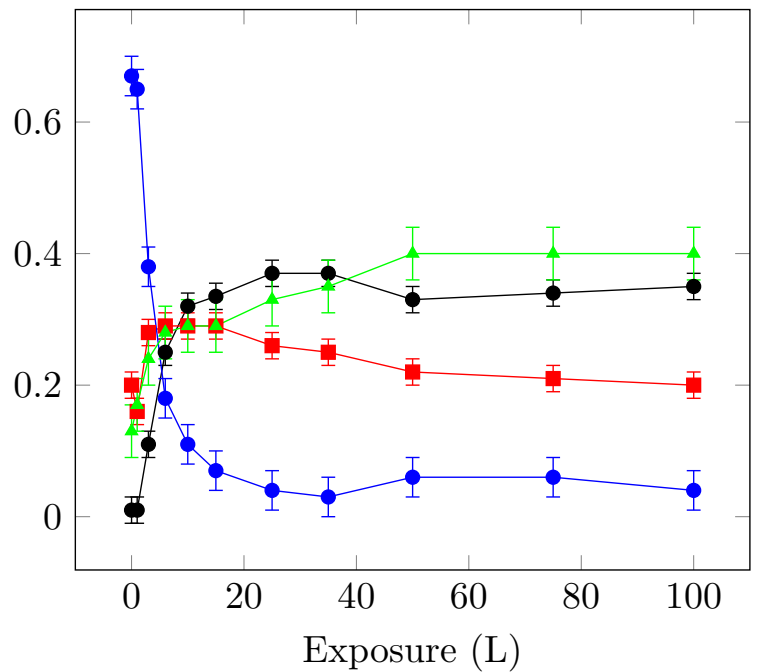

Figure 6: Evolution of relative nitrogen component intensities as a function of oxygen exposure at (a) RT and (b) $250^{\circ} \mathrm{C}$.

around $580 \mathrm{eV}$. The growth of $\mathrm{Cr}_{2} \mathrm{O}_{3}$ stops, or at least significantly slows at $10 \mathrm{~L}$ as beyond this point we observe no significant changes in the spectra. Equally, the amount of $\mathrm{CrN}$ at the surface reaches it maximum relative intensity between 6 and $10 \mathrm{~L}$ before levelling off. As $\mathrm{CrN}$ is present at the outermost surface of the oxide-free alloy, on top of which the oxide will grow, and is considered as a nucleation site $[29,30]$, one's immediate thought may be to expect a decrease in the relative amount of $\mathrm{CrN}$ detected. We can consider a few possibilities as to why this is not the case. Firstly, it may be due to the morphology of the oxide, with it being previously shown that the surface is not a completely homogeneous oxide layer but rather islands of oxide [29], suggesting that we will still have large areas of the surface with $\mathrm{CrN}$ at the outermost surface. Secondly, rearrangement of the surface may continue beyond the early phase, resulting in steady state production of surface $\mathrm{CrN}$, which then stops as the surface becomes saturated with oxygen. Figure $7 \mathrm{~b}$ shows that upon saturation with oxygen, metallic chromium represents $25-30 \%$ of the overall intensity associated with chromium. Iron is less readily oxidised than chromium at RT, with approximately $70 \%$ of the intensity of the iron spectrum being attributed to its elemental form. $\mathrm{Fe}^{3+}$ is found to be more common than $\mathrm{Fe}^{2+}$ at exposures beyond $6 \mathrm{~L}$. In the case of molybdenum, two oxidation states are observed, those of $\mathrm{Mo}^{4+}$ and $\mathrm{Mo}^{6+}$, with the former being found in a larger amount beyond exposures of $10 \mathrm{~L}$. The most two common oxides associated with these oxidation states are $\mathrm{MoO}_{2}$ and $\mathrm{MoO}_{3}$. At saturation metallic molybdenum makes up around $52 \%$ of the total intensity. 
Figure 7 shows that at $250{ }^{\circ} \mathrm{C}$, we observe significantly more oxidation of the metallic components. Once more, chromium is only found in one of three states - metallic $\mathrm{Cr}^{0}$, oxidised $\mathrm{Cr}^{3+}$ and $\mathrm{Cr}^{3+}$ nitride. The oxide to metal ratio has an initial rapid increase during the first $15 \mathrm{~L}$, before a significant reduction of the rate of oxidation. The $\mathrm{CrN}$ signal is at its maximum relative intensity between 6 and $25 \mathrm{~L}$ before it begins to decrease due to attenuation of the signal caused by growth of the oxide on top, indicating that this $\mathrm{CrN}$ species is mainly present close to the oxide-alloy interface. A steady-state supply production of $\mathrm{CrN}$ that is converted into chromium oxide cannot be ruled out. As previously stated, the signal associated with $\mathrm{N}_{b}$ decreases much faster at $250{ }^{\circ} \mathrm{C}$ than at RT, with this factor being used to explain the enhanced reactivity towards oxygen during the nucleation period. We do, however, observe a similar trend in the evolution of the nitrogen species for both temperatures (Figure 6). In the two cases we observe significant diminution of $\mathrm{N}_{b}$ with increased relative intensity of $\mathrm{N}_{s}, \mathrm{~N}_{i}$ and $\mathrm{N}_{m}$. The former, attributed to CrN formed at the oxide-alloy interface decreases after $25 \mathrm{~L}$ owed to attenuation of the signal, with this behaviour also reflected in Figure $7 \mathrm{~b}$. Similar to what we saw at $\mathrm{RT}, \mathrm{Fe}^{2+}$ is primarily formed during the initial stages of oxidation $(0-10 \mathrm{~L})$. Beyond these exposures at $250^{\circ} \mathrm{C}$, the relative amount of $\mathrm{Fe}^{3+}$ increases continuously, with the rate of its formation decreasing steadily after $15 \mathrm{~L}$. This corresponds with a decrease in the relative amount of metallic iron, whilst that of $\mathrm{Fe}^{2+}$ remains stable. It is possible that the higher temperature promotes further oxidation of $\mathrm{Fe}^{2+}$ to $\mathrm{Fe}^{3+}$, although, for this to be the case there is the requirement of $\mathrm{Fe}^{2+}$ being continuously formed from the metallic iron supply in the modified alloy region beneath the oxide film. Equally, it is possible that beyond this early nucleation period in which $\mathrm{Fe}^{2+}$ forms, metallic iron is directly converted to $\mathrm{Fe}^{3+}$. Regardless of the mechanism, it is clear that oxidation at $250{ }^{\circ} \mathrm{C}$ allows for increased diffusion of the iron through the oxide, resulting in an increase in the amount of oxide species present upon oxygen saturation. The two oxides of molybdenum behave differently to those of iron. In this case, the relative intensity of both $\mathrm{Mo}^{4+}$ and $\mathrm{Mo}^{6+}$ shown in Figure $7 \mathrm{c}$ increases steadily, with the ratio of the former to the latter always between values of $1-1.3$ at exposures of $6-100 \mathrm{~L}$. The ratio decreases slightly as the oxygen exposure increases, however, not as significantly as seen in the case of iron. Given that at an exposure of $3 \mathrm{~L}$ at $250{ }^{\circ} \mathrm{C}$ we attribute changes in the molybdenum spectrum to $\mathrm{Mo}^{4+}$ with no $\mathrm{Mo}^{6+}$ character, it could be suggested that in the case of molybdenum the metal is first converted into $\mathrm{Mo}^{4+}$ which is then further oxidised at higher exposures of oxygen. For all three elements we observe a decrease in the intensity associated with the metal which is owed to attenuation of the signal by the growth of the oxide. 
(a) $\mathrm{Fe}$
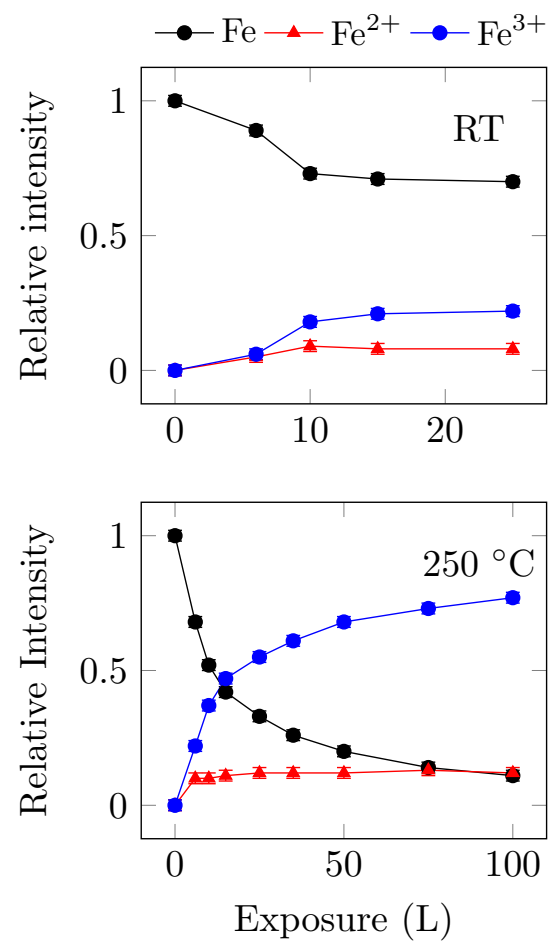

(b) $\mathrm{Cr}$
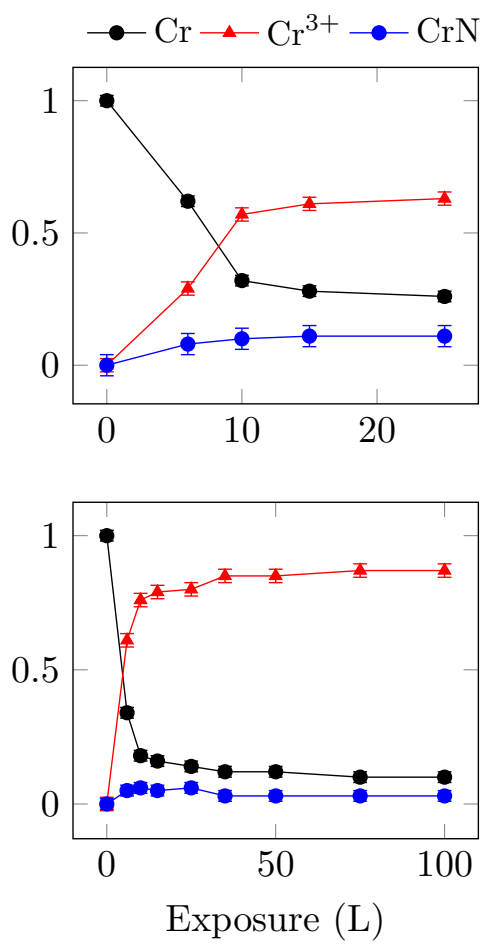

(c) $\mathrm{Mo}$
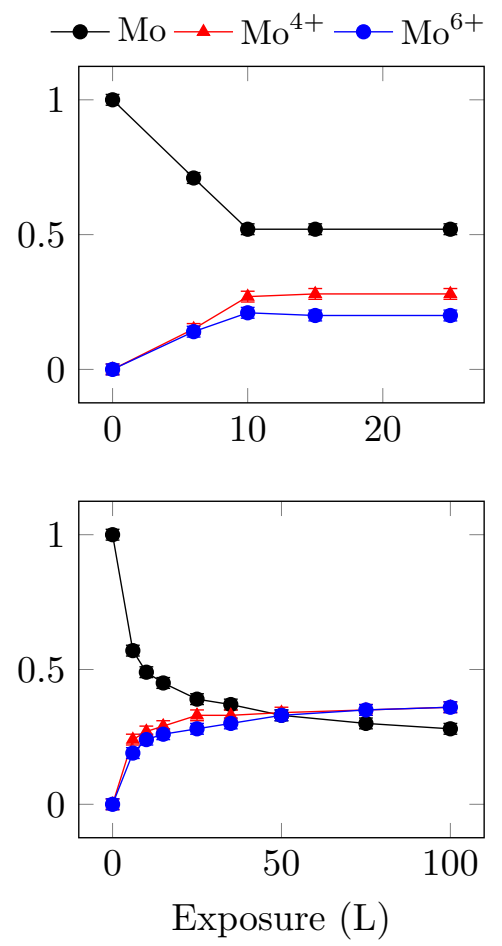

Figure 7: Evolution of (a) iron, (b) chromium and (c) molybdenum at RT (top) between 0-25 L, and $250{ }^{\circ} \mathrm{C}$ (bottom) between $0-100 \mathrm{~L}$ oxygen exposure at a $45^{\circ}$ take-off angle. 


\subsection{Composition of the oxide layer}

Previous work has shown that there are no defined layers formed within the oxide layer on austenitic stainless steels; however, layered models have frequently been used in order to describe the system in more depth with regards to their thickness, stratification and composition $[7,8,19,32,44]$. By taking into account key factors, such as the mean-free path, intensity and emission angle of the electrons, along with the atomic density, we can calculate the thickness and composition of the oxide. More information can be found on this in the supplementary information. It is important to note that the following work does not account for the heterogeneities, both morphological and chemical, of the surface which have been shown to form $[29,33]$. These heterogeneities may lead to differences in the calculated and actual thickness of the film which in turn has an influence on the calculated composition. This simplified model, which assumes a homogeneous distribution of the species within the oxide film, provides a good approximation of the composition, stratification and thickness of the oxide which allows us to better understand the growth of the film. Figure 8 shows the variation of the composition of both the oxide film and the modified alloy underneath as a function of the oxygen exposure at both RT and $250{ }^{\circ} \mathrm{C}$. At ambient temperature (Figure 8a), the oxide is found to be enriched in $\mathrm{Cr}^{3+}$, with it making up approximately $48 \%$ of the film after an exposure of $6 \mathrm{~L}$. At the same time the amounts of $\mathrm{Fe}^{2+}$ and $\mathrm{Fe}^{3+}$ are equal, each making up around $16 \%$. CrN, which in this case has been assigned to the oxide layer, is at its maximum percentage in terms of contribution to the overall composition of the film formed on top of the modified alloy after an exposure of 6 L. Oxidised molybdenum never goes above more than a few percent of the film's composition, indicating that at no point is it enriched. Between 6 and $15 \mathrm{~L}$ $\mathrm{Fe}^{3+}$ growth becomes more dominant and increases its overall percentage of the composition. At no point during the oxidation process is molybdenum found to be significantly enriched within the oxide film. At the saturation point we have an oxide film with the composition $\mathrm{Fe}-50 \mathrm{Cr}-2 \mathrm{Mo}$, with a calculated thickness of $0.8 \mathrm{~nm}$. Comparatively, when the oxide formed at $250{ }^{\circ} \mathrm{C}$ is of an

approximate thickness of $0.7 \mathrm{~nm}$ (after an exposure of $6 \mathrm{~L}$ ), the composition is calculated to be $\mathrm{Fe}-48 \mathrm{Cr}-2 \mathrm{Mo}$, which is almost identical to the composition of the oxide of $0.8 \mathrm{~nm}$ thickness formed at RT. The composition of the modified alloy at RT, displayed in Figure 8b, is found to be initially rich in chromium as a result of the annealing process carried out to prepare the clean surface prior to oxidation. This metal is quickly consumed during the early stages of oxide formation and at $10 \mathrm{~L}$ the chromium contribution to the modified alloy has reduced from $31 \%$ on the clean surface to just $14 \%$, which is much closer to that of the bulk amount. As the intensity of the metallic chromium 
diminishes, that of the iron increases, reaching a peak contribution of $76 \%$. Concurrently, we begin to see the modified alloy become enriched in metallic nickel, which is owed to the fact that iron and chromium from the alloy are being transported through the oxide film and oxidising. At the saturation point, the modified alloy has the a composition of $\mathrm{Fe}-12 \mathrm{Cr}-10 \mathrm{Ni}-2 \mathrm{Mo}$.

Similar behavioural patterns can be seen during the first $6 \mathrm{~L}$ of oxygen exposure at $250{ }^{\circ} \mathrm{C}$ in Figure 8c, with chromium oxide making up $45 \%$ of the oxide film. Whereas at RT we saw equal amounts of $\mathrm{Fe}^{2+}$ and $\mathrm{Fe}^{3+}$ at this exposure, the evolution is different at the higher temperature, now with significantly more $\mathrm{Fe}^{3+}$. As expected, the relative amount of $\mathrm{CrN}$ peaks at low exposures of oxygen before reducing to negligible amounts. Beyond an exposure of $6 \mathrm{~L}$ the formation of $\mathrm{Fe}^{3+}$ oxide becomes dominant, aided by the increased mobility of metallic iron through the oxide lattice. The relative amount of $\mathrm{Fe}^{2+}$ remains stable as the oxygen exposure increases. Once again, no enrichment of molybdenum is observed. After a $100 \mathrm{~L}$ exposure at $250{ }^{\circ} \mathrm{C}$, the composition of the oxide film was Fe-19Cr-1Mo. The thickness of the film was calculated as $2.1 \mathrm{~nm}( \pm 0.1 \mathrm{~nm})$, which is similar to values reported on comparable surfaces $[7,8,32]$. The calculated composition suggests that oxidised molybdenum is not enriched within the film. With regards to the composition of the modified alloy at $250{ }^{\circ} \mathrm{C}$ in Figure $8 \mathrm{~d}$, we essentially see a continuation of the trends exhibited at room temperature where we have the initial decrease in the relative amount of chromium in conjunction with an enrichment of iron and nickel. Beyond $6 \mathrm{~L}$, when growth of iron oxide begins to dominate and metallic iron is consumed, the lack of nickel oxide formed results in a significant enrichment of the metal underneath the oxide film. After a $100 \mathrm{~L}$ exposure at $250{ }^{\circ} \mathrm{C}$, the composition of the modified alloy was $\mathrm{Fe}-10 \mathrm{Cr}-23 \mathrm{Ni}-1 \mathrm{Mo}$, indicating that further oxidation of 316 stainless steel samples increases the amount of metallic nickel enriched in the modified alloy region.

Angular analysis of the high resolution spectra, carried out at photoelectron take-off angles of $45^{\circ}$ and $90^{\circ}$, was performed to verify the in-depth distribution of the elements within the oxide film. Figure 9 shows composition of the oxide film as a function of oxygen exposure at $250{ }^{\circ} \mathrm{C}$, at both take-off angles. If the film were completely homogeneous, we would expect the same results regardless of the angle, however, here this is not the case, indicating that the in-depth distribution of the oxidised species is somewhat heterogeneous. This suggests that the model used to estimate the thickness and composition of the film is imperfect, however, the differences in the results are not significant enough that the model is not a good approximation. By decreasing the take-off angle we become more surface sensitive and therefore would expect species found closer to the surface to have a higher relative intensity than at larger angles. The opposite can be said in that 

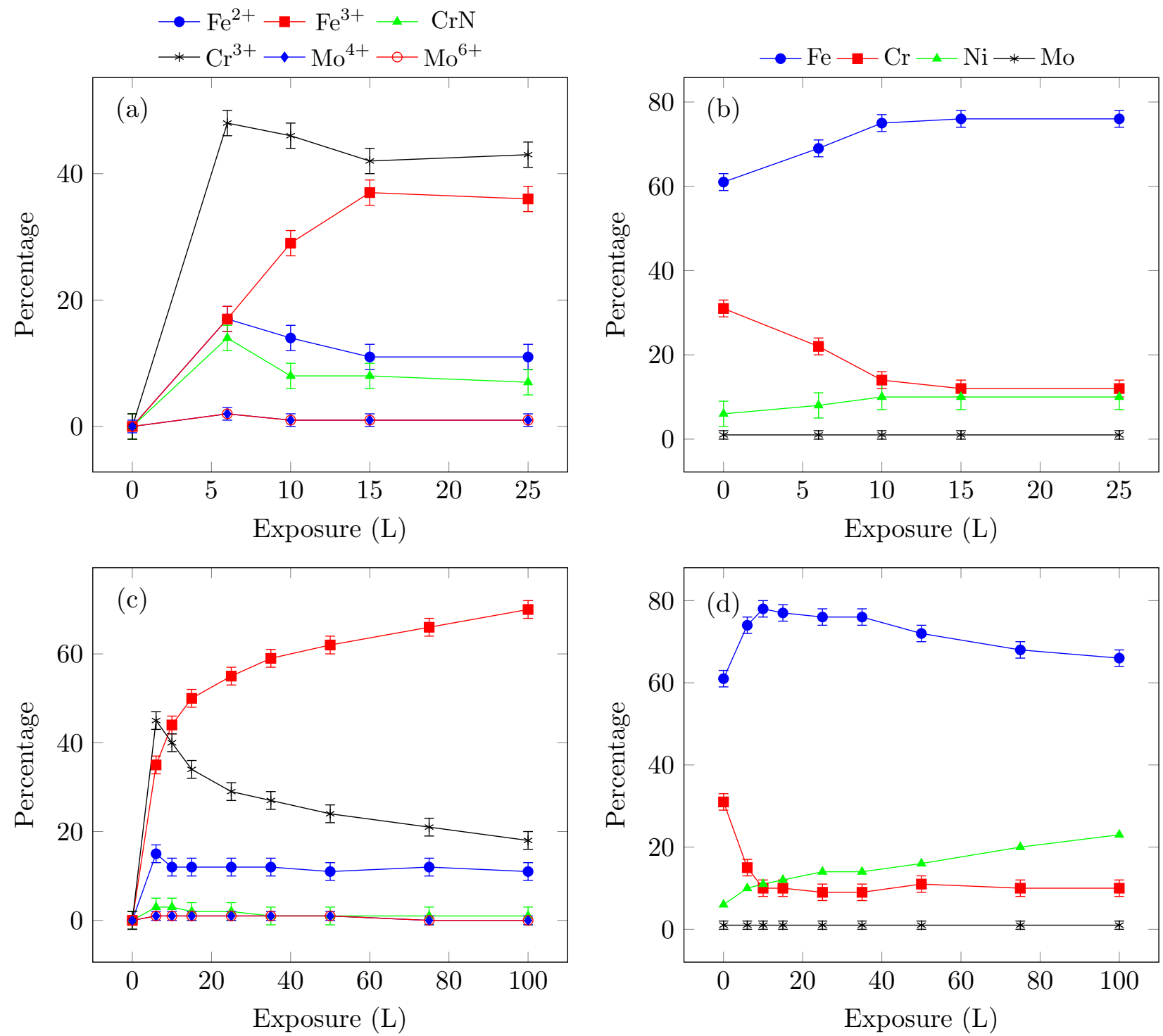

Figure 8: Composition of the (a) oxide at RT, (b) modified alloy at RT, (c) oxide at $250{ }^{\circ} \mathrm{C}$, and (d) modified alloy at $250{ }^{\circ} \mathrm{C}$, as a function of oxygen exposure. 
we would expect to see a decrease in the relative intensity for species found closer to the alloy-oxide interface. From the data in Figure 9, we can see that $\mathrm{Fe}^{2+}$ is more enriched closer to alloy-oxide interface, as evidenced by the fact that we have a consistently stronger intensity when probing deeper into the surface. This can be combined with what was shown earlier where it was suggested that $\mathrm{Fe}^{2+}$ is formed early on in the oxidation process before growth of the oxide film is dominated by $\mathrm{Fe}^{3+}$. This claim is further backed up when we see that $\mathrm{Fe}^{3+}$ is more enriched in the outer part of the oxide film. Chromium oxide is also found more enriched closer to oxide-alloy interface, once more evidenced by the fact that we have a decreased relative intensity when using a more surface sensitive angle. Again referring back to earlier in the text, this is perhaps not too surprising seeing as it was shown that chromium oxide growth dominates the initial stages of oxidation. The data relating to distribution of $\mathrm{CrN}$ suggests that it too is found enriched at the alloy-oxide interface, as we would expect based on previously shown data, although given the relatively small amounts present beyond $15 \mathrm{~L}$ the uncertainty using this method is significant. The two angles were not enough to suggest that molybdenum is found enriched at any part of the oxide film, although we were able to compare the relative ratios of $\mathrm{Mo}^{4+}$ to $\mathrm{Mo}^{6+}$ at the two angles and it showed that the two oxides are equally distributed within the film.

Based on all these observations and previous work on other model stainless steel samples, it is possible to propose a mechanism for the very initial stages of oxidation of FeCrNiMo stainless steels, the first reported of its kind. Upon introduction of oxygen, the clean and well-organised surface enriched in chromium and nitrogen as a result of elemental segregation caused during the annealing process, is modified due to the formation chromium nitride species that behave as nucleation sites for growth of chromium oxide, most likely $\mathrm{Cr}_{2} \mathrm{O}_{3}$. During this initial nucleation phase, we also observe growth of iron oxide, with iron found in both the +2 and +3 oxidation state. The results suggest that the oxidation of molybdenum is delayed until after the process has already begun on iron and chromium. Once the oxide film becomes sufficiently thick, the growth of the oxide film is increased thanks to augmentation of the amount of $\mathrm{Fe}^{3+}$ oxide which may be directly oxidised from the metal or via further oxidation of $\mathrm{Fe}^{2+}$. Once an oxide thickness of approximately $0.8 \mathrm{~nm}$ is reached, which in this case corresponds to an exposure between 10-15 L, transport of iron through the oxide film is no longer feasible in the given conditions and the surface saturates. At $250{ }^{\circ} \mathrm{C}$ the initial oxide growth follows a similar regime; however, the higher temperature allows for increased mobility of the atoms through the oxide film which results in further oxidation of the sample, which at this point can mainly be attributed to oxidation of iron. As the thickness of the oxide increases 


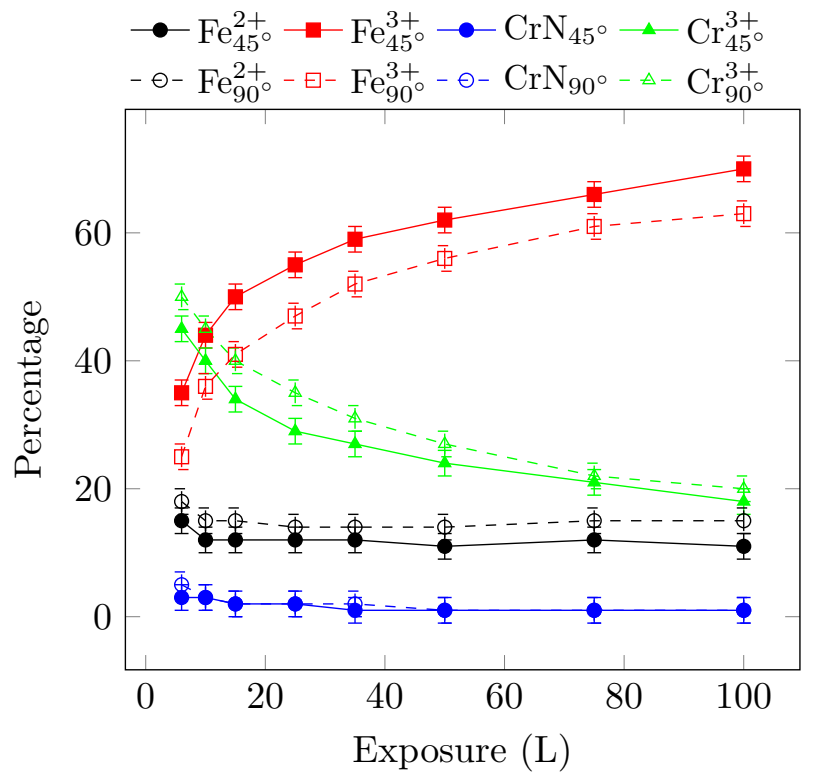

Figure 9: Composition of oxide film at $250{ }^{\circ} \mathrm{C}$ as a function of oxygen exposure at $45^{\circ}$ and $90^{\circ}$ photoelectron take-angles.

even at these elevated temperatures atom transport through the oxide lattice becomes difficult and the rate of oxide growth falls dramatically.

\section{Conclusion}

XPS high resolution, angular and in situ analysis has been used to to provide unprecedented insight into the mechanism for very first stages of oxide growth on an FeCrNiMo austenitic stainless steel. The annealing process, necessary for surface preparation, results in segregation of chromium and nitrogen on the clean surface.In situ snapshot measurements showed evidence for co-segregation of chromium and nitrogen above $600{ }^{\circ} \mathrm{C}$, during annealing process. Analysis of the chromium snapshot measurements indicated that it was already segregating below this temperature suggesting that there are two mechanisms for chromium segregation during annealing on FeCrNiMo stainless steels.

The initial stages of oxidation result in rearrangement of the surface and the formation of $\mathrm{CrN}$ species that behave as nucleation sites for growth of $\mathrm{Cr}_{2} \mathrm{O}_{3}$. Iron oxides, present as both $\mathrm{Fe}^{2+}$ and $\mathrm{Fe}^{3+}$, are found to nucleate at the same time as as those of chromium. Initial oxidation of molybdenum was found to occur after these two elements had already begun to oxidise. At no point was nickel found in an oxidised form within the oxide film, however, metallic nickel became more enriched within the modified alloy region as the oxide grew thicker. The initial stages of oxidation 
follow standard thermodynamic principles, however it is once the oxide film becomes significantly thick that kinetic parameters become the presiding factor with the iron cation's increased mobility through the film resulting in the main contributor to continued oxidation being $\mathrm{Fe}^{3+}$ oxide. Oxidation at $250{ }^{\circ} \mathrm{C}$ was found to result in a faster rate of oxidation which is attributed to the enhanced rate of surface reorganisation and production of $\mathrm{CrN}$ that behaves as a nucleation site of oxidation of chromium.

Angular analysis was used in determining the in-depth distribution of the oxidised species within the oxide film. It was shown that $\mathrm{Cr}^{3+}$ and $\mathrm{Fe}^{2+}$ are found enriched closer to the modified alloy-oxide interface with $\mathrm{Fe}^{3+}$ found predominantly at the outer portion of the film. Oxidised molybdenum was found as both $\mathrm{Mo}^{4+}$ and $\mathrm{Mo}^{6+}$, with neither found to be enriched or depleted at a given depth within the film.

RT oxidation resulted in surface saturation after a total oxygen exposure of between 10 and $15 \mathrm{~L}$, with the composition of the oxide determined as $\mathrm{Fe}-50 \mathrm{Cr}-2 \mathrm{Mo}$. At this stage the thickness was found to be approximately $0.8 \mathrm{~nm}$. The rate of oxidation at $250{ }^{\circ} \mathrm{C}$ significantly reduced between 15 and $25 \mathrm{~L}$, with the oxide thickness determined as approximately $2.1 \mathrm{~nm}$ after an exposure of $100 \mathrm{~L}$. The composition of the oxide at this stage was $\mathrm{Fe}-19 \mathrm{Cr}-1 \mathrm{Mo}$.

The present work, focusing on the growth of the oxide on austenitic stainless steel, helps to build on the fundamental knowledge relating to how the oxidation mechanism prior to passivation can later influence the properties of the passive film formed on austenitic stainless steels.

\section{Acknowledgements}

This project has received funding from the European Research Council (ERC) under the European Union's Horizon 2020 research and innovation program (ERC Advanced Grant No. 741123, Corrosion Initiation Mechanisms at the Nanometric and Atomic Scales : CIMNAS). Région Île-deFrance is acknowledged for partial funding of the UHV equipment.

\section{References}

[1] D. D. Macdonald, Passivity-the key to our metals-based civilization, Pure and Applied Chemistry 71 (6) (1999) 951-978.

[2] V. Maurice, H. Peng, L. H. Klein, A. Seyeux, S. Zanna, P. Marcus, Effects of molybdenum 
on the composition and nanoscale morphology of passivated austenitic stainless steel surfaces, Faraday discussions 180 (2015) 151-170.

[3] J. W. Schultze, M. Lohrengel, Stability, reactivity and breakdown of passive films. Problems of recent and future research, Electrochimica Acta 45 (15-16) (2000) 2499-2513.

[4] P. Schmuki, From bacon to barriers: a review on the passivity of metals and alloys, Journal of Solid State Electrochemistry 6 (3) (2002) 145-164.

[5] P. Marcus, Corrosion mechanisms in theory and practice, CRC press, 2011.

[6] M. Bojinov, G. Fabricius, T. Laitinen, K. Mäkelä, T. Saario, G. Sundholm, Influence of molybdenum on the conduction mechanism in passive films on iron-chromium alloys in sulphuric acid solution, Electrochimica Acta 46 (9) (2001) 1339-1358.

[7] B. Lynch, Z. Wang, L. Ma, E.-M. Paschalidou, F. Wiame, V. Maurice, P. Marcus, PassivationInduced Cr and Mo Enrichments of 316L Stainless Steel Surfaces and Effects of Controlled Pre-Oxidation, Journal of the Electrochemical Society 167 (14) (2020) 141509.

[8] B. Lynch, S. Neupane, F. Wiame, A. Seyeux, V. Maurice, P. Marcus, An XPS and ToFSIMS study of the passive film formed on a model FeCrNiMo stainless steel surface in aqueous media after thermal pre-oxidation at ultra-low oxygen pressure, Applied Surface Science (2021) 149435 .

[9] N. Sato, T. Noda, K. Kudo, Thickness and structure of passive films on iron in acidic and basic solution, Electrochimica Acta 19 (8) (1974) 471-475.

[10] S. El-Egamy, W. Badaway, Passivity and passivity breakdown of 304 stainless steel in alkaline sodium sulphate solutions, Journal of Applied Electrochemistry 34 (11) (2004) 1153-1158.

[11] G. Burstein, P. Marshall, Growth of passivating films on scratched 304L stainless steel in alkaline solution, Corrosion Science 23 (2) (1983) 125-137.

[12] P. Marcus, V. Maurice, H.-H. Strehblow, Localized corrosion (pitting): A model of passivity breakdown including the role of the oxide layer nanostructure, Corrosion Science 50 (9) (2008) $2698-2704$.

[13] M. Streicher, Pitting corrosion of $18 \mathrm{Cr}-8 \mathrm{Ni}$ stainless steel, Journal of the Electrochemical Society 103 (7) (1956) 375. 
[14] Y. Tsutsumi, A. Nishikata, T. Tsuru, Pitting corrosion mechanism of Type 304 stainless steel under a droplet of chloride solutions, Corrosion Science 49 (3) (2007) 1394-1407.

[15] G. H. Koch, M. P. Brongers, N. G. Thompson, Y. P. Virmani, J. H. Payer, Corrosion cost and preventive strategies in the United States, Tech. rep. (2002).

[16] P. A. Schweitzer, Corrosion of polymers and elastomers, CRC Press, 2006.

[17] G. Ilevbare, G. Burstein, The role of alloyed molybdenum in the inhibition of pitting corrosion in stainless steels, Corrosion Science 43 (3) (2001) 485-513.

[18] R. Qvarfort, Some observations regarding the influence of molybdenum on the pitting corrosion resistance of stainless steels, Corrosion Science 40 (2-3) (1998) 215-223.

[19] Z. Wang, A. Seyeux, S. Zanna, V. Maurice, P. Marcus, Chloride-induced alterations of the passive film on 316L stainless steel and blocking effect of pre-passivation, Electrochimica Acta 329 (2020) 135159.

[20] E. De Vito, P. Marcus, XPS study of passive films formed on molybdenum-implanted austenitic stainless steels, Surface and Interface Analysis 19 (1-12) (1992) 403-408.

[21] K. Hashimoto, K. Asami, K. Teramoto, An X-ray photo-electron spectroscopic study on the role of molybdenum in increasing the corrosion resistance of ferritic stainless steels in $\mathrm{HCl}$, Corrosion Science 19 (1) (1979) 3-14.

[22] J. Horvath, H. Uhlig, Critical potentials for pitting corrosion of Ni, Cr-Ni, Cr-Fe, and related stainless steels, Journal of the Electrochemical Society 115 (8) (1968) 791.

[23] M.-W. Tan, E. Akiyama, A. Kawashima, K. Asami, K. Hashimoto, The effect of air exposure on the corrosion behavior of amorphous Fe-8Cr-Mo-13P-7C alloys in $1 \mathrm{M} \mathrm{HCl}$, Corrosion Science 37 (8) (1995) 1289-1301.

[24] J.-B. Lee, Effects of alloying elements, Cr, Mo and N on repassivation characteristics of stainless steels using the abrading electrode technique, Materials Chemistry and Physics 99 (2-3) (2006) $224-234$.

[25] A. Elbiache, P. Marcus, The role of molybdenum in the dissolution and the passivation of stainless steels with adsorbed sulphur, Corrosion Science 33 (2) (1992) 261-269. 
[26] A. Pardo, M. Merino, A. Coy, F. Viejo, R. Arrabal, E. Matykina, Effect of Mo and Mn additions on the corrosion behaviour of AISI 304 and 316 stainless steels in $\mathrm{H}_{2} \mathrm{SO}_{4}$, Corrosion Science 50 (3) (2008) 780-794.

[27] A. Pardo, M. Merino, A. Coy, F. Viejo, R. Arrabal, E. Matykina, Pitting corrosion behaviour of austenitic stainless steels-combining effects of Mn and Mo additions, Corrosion Science 50 (6) (2008) 1796-1806.

[28] T. Massoud, V. Maurice, L. H. Klein, A. Seyeux, P. Marcus, Nanostructure and local properties of oxide layers grown on stainless steel in simulated pressurized water reactor environment, Corrosion Science 84 (2014) 198-203.

[29] L. Ma, F. Wiame, V. Maurice, P. Marcus, Origin of nanoscale heterogeneity in the surface oxide film protecting stainless steel against corrosion, npj Materials Degradation 3 (1) (2019) $1-9$.

[30] L. Ma, F. Wiame, V. Maurice, P. Marcus, Stainless steel surface structure and initial oxidation at nanometric and atomic scales, Applied Surface Science 494 (2019) 8-12.

[31] L. Ma, B. Lynch, F. Wiame, V. Maurice, P. Marcus, Nanoscale early oxidation mechanisms of model FeCrNi austenitic stainless steel surfaces at room temperature, Corrosion Science (2021) 109653.

[32] L. Ma, F. Wiame, V. Maurice, P. Marcus, New insight on early oxidation stages of austenitic stainless steel from in situ XPS analysis on single-crystalline $\mathrm{Fe}-18 \mathrm{Cr}-13 \mathrm{Ni}$, Corrosion Science 140 (2018) 205-216.

[33] L. Ma, E.-M. Pascalidou, F. Wiame, S. Zanna, V. Maurice, P. Marcus, Passivation mechanisms and pre-oxidation effects on model surfaces of FeCrNi austenitic stainless steel, Corrosion Science 167 (2020) 108483.

[34] Copyright (c) 2005 casa software ltd.

URL http://www. casaxps.com/

[35] C. R. Brundle, B. V. Crist, X-ray photoelectron spectroscopy: A perspective on quantitation accuracy for composition analysis of homogeneous materials, Journal of Vacuum Science \& Technology A: Vacuum, Surfaces, and Films 38 (4) (2020) 041001. 
[36] H. Ali-Löytty, P. Jussila, M. Hirsimäki, M. Valden, Influence of CrN surface compound on the initial stages of high temperature oxidation of ferritic stainless steel, Applied Surface Science 257 (17) (2011) 7783-7791.

[37] H. Grabke, R. Dennert, B. Wagemann, The effect of S, N, and C on the oxidation of Ni-20\% Cr and Fe-20\% Cr, Oxidation of metals 47 (5) (1997) 495-506.

[38] M. Chase, NIST-JANAF Thermochemical Tables, 4th Edition, American Institute of Physics, 1998.

[39] G. Allen, J. Dyke, S. Harris, A. Morris, A surface study of the oxidation of type 304L stainless steel at $600 \mathrm{~K}$ in air, Oxidation of metals 29 (5) (1988) 391-408.

[40] T.-C. Lin, G. Seshadri, J. A. Kelber, A consistent method for quantitative XPS peak analysis of thin oxide films on clean polycrystalline iron surfaces, Applied Surface Science 119 (1-2) (1997) 83-92.

[41] E. Clauberg, J. Janověc, C. Uebing, H. Viefhaus, H. Grabke, Surface segregation on Fe-25\% Cr-2\% Ni-0.14\% Sb-N, S (100) single crystal surfaces, Applied Surface Science 161 (1-2) (2000) 35-46.

[42] C. Uebing, V. Scheuch, M. Kiskinova, H. Bonzel, Segregation of ordered CrN and CrC surface phases on a Fe-15\% Cr (100) crystal, Surface Science 321 (1-2) (1994) 89-99.

[43] P. Marcus, M. E. Bussell, XPS study of the passive films formed on nitrogen-implanted austenitic stainless steels, Applied surface science 59 (1) (1992) 7-21.

[44] V. Maurice, W. Yang, P. Marcus, X-Ray photoelectron spectroscopy and scanning tunneling microscopy study of passive films formed on (100) Fe-18Cr-13Ni single-crystal surfaces, Journal of the Electrochemical Society 145 (3) (1998) 909. 